\title{
Increased Cardiovascular Disease, Resource Use, and Costs Before the Clinical Diagnosis of Diabetes in Veterans in the Southeastern U.S.
}

\author{
Darin E. Olson, MD, $P h D^{1,2}$, Ming Zhu, $P h D^{3,9}$, Qi Long, $P H D^{3}$, Diana Barb, MD², Jeehea S. Haw, MD², \\ Mary K. Rhee, MD, MSCR ${ }^{1,2}$, Arun V. Mohan, MD, MBA ${ }^{4}$, Phyllis I. Watson-Williams, MD", \\ Sandra L. Jackson, MPH ${ }^{1,6}$, Anne M. Tomolo, MD, MPH ${ }^{1,4}$, Peter W. F. Wilson, MD ${ }^{7,5}$, \\ K. M. Venkat Narayan, MD, MBA, MPH ${ }^{7}$, Joseph Lipscomb, PhD ${ }^{8}$, and Lawrence S. Phillips, MD ${ }^{1,2}$
}

\begin{abstract}
'Atlanta VA Medical Center, Decatur, GA, USA; '2Division of Endocrinology and Metabolism, Emory University School of Medicine, Atlanta, GA, USA; ${ }^{3}$ Department of Biostatistics and Bioinformatics, Emory University, Atlanta, GA, USA; ${ }^{4}$ Division of General Internal Medicine, Emory University School of Medicine, Atlanta, GA, USA; ${ }^{5}$ Division of Cardiology, Department of Medicine, Emory University School of Medicine, Atlanta, GA, USA; ${ }^{6}$ Nutrition and Health Sciences, Graduate Division of Biological and Biomedical Sciences, Emory University, Atlanta, GA, USA; ${ }^{7}$ Department of Global Health, Emory University, Atlanta, GA, USA; ${ }^{8}$ Department of Health Policy and Management, Rollins School of Public Health, Emory University, Atlanta, GA, USA; ${ }^{9}$ Abbott Laboratories, North Chicago, IL, USA.
\end{abstract}

IMPORTANCE: Screening for diabetes might be more widespread if adverse associations with cardiovascular disease (CVD), resource use, and costs were known to occur earlier than conventional clinical diagnosis.

OBJECTIVE: The purpose of this study was to determine whether adverse effects associated with diabetes begin prior to clinical diagnosis.

DESIGN: Veterans with diabetes were matched 1:2 with controls by follow-up, age, race/ethnicity, gender, and VA facility. CVD was obtained from ICD-9 codes, and resource use and costs from VA datasets.

SETTING: VA facilities in SC, GA, and AL.

PARTICIPANTS: Patients with and without diagnosed diabetes.

MAIN OUTCOME MEASURES: Diagnosed CVD, resource use, and costs.

RESULTS: In this study, the 2,062 diabetic patients and 4,124 controls were 63 years old on average, $99 \%$ male, and $29 \%$ black; BMI was 30.8 in diabetic patients vs. 27.8 in controls $(p<0.001)$. CVD prevalence was higher and there were more outpatient visits in Year -4 before diagnosis through Year +4 after diagnosis among diabetic vs. control patients (all $p<0.01$ ); in Year -2 , CVD prevalence was $31 \%$ vs. $24 \%$, and outpatient visits were 22 vs. 19 per year, respectively. Total VA costs/year/veteran were higher in diabetic than control patients from Year -4 (\$4,083 vs. $\$ 2,754)$ through Year +5 (\$8,347 vs. \$5,700) $(p<0.003)$ for each, reflecting underlying increases in outpatient, inpatient, and pharmacy costs

Electronic supplementary material The online version of this article (doi:10.1007/s11606-014-3075-7) contains supplementary material, which is available to authorized users.

Received December 6, 2013

Revised August 26, 2014

Accepted September 28, 2014

Published online January 22, 2015 $(p<0.05$ for each). Regression analysis showed that diabetes contributed an average of $\$ 1,748 /$ year to costs, independent of CVD $(p<0.001)$.

CONCLUSIONS AND RELEVANCE: VA costs per veteran are higher-over $\$ 1,000 /$ year before and $\$ 2,000 /$ year after diagnosis of diabetes-due to underlying increases in outpatient, inpatient, and pharmacy costs, greater number of outpatient visits, and increased CVD. Moreover, adverse associations with veterans' health and the VA healthcare system occur early in the natural history of the disease, several years before diabetes is diagnosed. Since adverse associations begin before diabetes is recognized, greater consideration should be given to systematic screening in order to permit earlier detection and initiation of preventive management. Keeping frequency of CVD and marginal costs in line with those of patients before diabetes is currently diagnosed has the potential to save up to $\$ 2$ billion a year.

KEY WORDS: diabetes; health care cost; cardiovascular disease; prediabetes.

\section{ABBREVLATIONS}

$\begin{array}{ll}\text { Alc } & \text { Hemoglobin Alc } \\ \text { CAD } & \text { Coronary artery disease } \\ \text { CBD } & \text { Cerebrovascular disease } \\ \text { CDW } & \text { Corporate Data Warehouse } \\ \text { CVD } & \text { Cardiovascular disease } \\ \text { DPP } & \text { United States Diabetes Prevention Program } \\ \text { GEE } & \text { Generalized Estimating Equations } \\ \text { HERC } & \text { Health Economics Resource Center } \\ \text { KPNW } & \text { Kaiser Permanente Northwest } \\ \text { MEPS } & \text { Medical Expenditure Panel Survey } \\ \text { NGT } & \text { Normal glucose-tolerant (on an OGTT) } \\ \text { NHANES } & \text { National Health and Nutrition Examination Survey } \\ \text { OGTT } & \text { Oral glucose tolerance test } \\ \text { PVD } & \text { Peripheral vascular disease }\end{array}$


SIGT

$\mathrm{VA}$

VISN
Screening for Impaired Glucose Tolerance study Veterans Health Administration

Veterans Integrated Service Network (VA Region)

J Gen Intern Med 30(6):749-57

DOI: $10.1007 / \mathrm{s} 11606-014-3075-7$

(C) Society of General Internal Medicine 2015 (outside the USA) 2015

\section{INTRODUCTION}

The Veterans Health Administration (VA) oversees the largest integrated healthcare system in the U.S., and diabetes is a common and costly problem for the VA. The veteran population is rich in minorities and older patients - groups at higher risk of developing diabetes - and in 2000 , close to $20 \%$ of VA outpatients had diabetes. ${ }^{1}$ The result is increased morbidity and mortality for VA patients, and increased resource use and costs for the VA. In 1998, VA diabetes costs were estimated at $\$ 1.67$ billion, $3.9 \%$ of total VA expenditures, ${ }^{2}$ and in $2000,28 \%$ of pharmacy costs were attributed to diabetes. ${ }^{3}$ Since that time, total direct medical expenditures attributable to diabetes in the U.S. have increased from approximately $\$ 92$ billion in $2002^{4}$ to $\$ 116$ billion in $2007^{5}$ and $\$ 176$ billion in $2012^{6}$; average annual medical expenditures for a person with diagnosed diabetes were estimated to be $\$ 11,744$ in $2007^{5}$ and $\$ 13,700$ in $2012 .^{6}$

Veterans with diabetes often have multiple health problems, and CVD is a complication in approximately $50 \%$ of cases. $^{7}$ Moreover, while metabolic control in veterans tends to be better than in non-veterans, ${ }^{8,9}$ studies show that many veterans have elevated A1c levels, ${ }^{10}$ even after adjusting for comorbidity and life expectancy. ${ }^{10,11}$ In particular, despite evidence-based guidelines showing "a strong case for intensive control among patients free, or nearly free, of diabetic microvascular disease" ${ }^{~} 12$ early in their natural histories, many veterans do not have good diabetes control.

Making the diagnosis early allows a sustained benefit from medications such as metformin. ${ }^{13}$ However, we found the initial diagnosis of diabetes to be delayed in veterans in the southeastern U.S., with delays averaging 1-2 years after two occurrences of hyperglycemia; the diagnosis was often based on nonstandard criteria, although it was usually correct. ${ }^{14}$ While access to care is more uniform in the VA than in the U.S. in general, we also found disparities in how the diagnosis was made, since A1c levels at diagnosis were higher in black than in white veterans $(7.8 \%$ vs. $7.1 \%)$, a difference too great to be explained by differences in age, sex, BMI, and the glucose-independent associations between race and A1c. ${ }^{15,16}$ Disparities can be alleviated when care is guided by uniform algorithms for management, as we have shown at Grady Hospital in Atlanta. ${ }^{17}$ We further found that A1c levels would be substantially lower if unrecognized diabetes were identified by screening with oral glucose tolerance tests (OGTTs). A1c levels averaged $6.2 \%$ in OGTT-detected diabetes. ${ }^{18}$

Since diabetes is asymptomatic early in its natural history, earlier diagnosis would require screening. However, systematic screening to identify patients with previously undiagnosed diabetes is uncommon both in the VA and in other healthcare systems. ${ }^{19}$ While national and international diabetes associations call for screening of most adults over the age of 4050 years and screening of all adults with risk factors, ${ }^{20-22}$ other agencies recommend testing only in the setting of hypertension, ${ }^{23,24}$ hyperlipidemia, ${ }^{23}$ or as part of risk evaluation in patients with CVD. ${ }^{25,26}$

Screening might be more common in large healthcare systems if adverse associations with diabetes, such as increased healthcare costs, were widely recognized to occur early in the natural history of the disease, at a time when adverse effects might be forestalled with preventive management. Higher rates of CVD, increased healthcare resource use, and higher costs have been reported before a clinical diagnosis of diabetes in data from the Nurses' Health Study, primary care clinics in the United Kingdom, and Kaiser Permanente Northwest (KPNW), respectively, ${ }^{27-}$ 31 but there has been no coordinated study of the time course of adverse associations with early diabetes within a single healthcare system. We sought to determine when the adverse associations with diabetes could be detected, using CVD as a measure of impact on health, and resource use and cost as measures of impact on the healthcare system, in veterans in the southeastern U.S. who received care through the VA. We demonstrated that CVD, resource use, and costs were all significantly and substantially increased four years prior to clinical diagnosis, and that costs rose further after the diagnosis was made.

\section{METHODS}

\section{Design}

We conducted a case-control analysis, similar to reports in the literature, ${ }^{27,28,31}$ using Corporate Data Warehouse (CDW) information on veterans in $\mathrm{SC}, \mathrm{GA}$, and $\mathrm{AL}$ receiving healthcare through Veterans Integrated Service Network (VISN) 7. This study was approved by the Institutional Review Board at Emory University.

For each patient, CDW outpatient "visits" included data associated with a given patient on outpatient visit days, even if an outpatient visit occurred on the day of hospitalization, an inpatient day, or the day of discharge. These outpatient data captured the date of each visit, all available information regarding the type of visit (emergency room, primary care, etc., using both stop codes and location description), and all associated ICD-9 codes. Inpatient "days" included data associated with the day of hospitalization and all hospital days as well as the day of discharge. For each day, data included 
the date, all available information regarding the type of hospital day (medicine, surgery, etc.), and all associated ICD-9 codes. Outpatient visits and inpatient days were sorted into one-year units before and after the index year (the year of initial diagnosis of diabetes, see below). The years prior to the index year were designated years $-1,-2$, etc., and the years after the index year were designated years $+1,+2$, etc. (see online Appendix, Fig. 1).

\section{Subjects}

We first selected patients with an initial diagnosis of diabetes on or after 10/1/2002, which provided at least four years for data to populate the CDW. The diagnosis was defined as previously validated ${ }^{10,14,15}$ by either a single use of the diabetes ICD-9 code $250 . x x$ in association with a primary care outpatient visit, any use of the code twice, or any prescription of a diabetes drug, following no use of the code, or use of a diabetes drug in the prior three years. We then restricted the analysis to diabetic patients receiving continuous primary care, defined as $\geq 5$ visits over $\geq 4$ fiscal years (FY) before and $\geq 4$ visits over $\geq 3 \mathrm{FY}$ after the "index" FY in which the diagnosis was made. In order to limit bias, diabetic patients were matched 1:2 with controls who had similar follow-up, age, race/ethnicity (including "unknown" if race was not identified), gender, and VA facility where care was provided, but no use of the diabetes ICD-9 code. The "index" FY for each control was assigned as the FY providing four years with at least five visits before the index year, and three years with at least four visits after the index year. Cases and controls thus had similar continuity of primary care, but neither cases nor controls were required to have visits and laboratory tests during each FY before, during, and after the index FY, which led to some variation in the number of cases and controls with the data during each FY. From 10/1/2002 through 11/25/2009, 381,898 patients without a diagnosis of diabetes and 92,514 patients with a diagnosis of diabetes (19.5\%) had at least one primary care visit in VISN 7, and from these, application of the criteria described above resulted in 6,244 potential diabetic patients and 9,550 potential control patients. Application of the matching criteria then resulted in 2,062 diabetic patients and 4,124 matched control patients.

Based on our previous studies showing that the diagnosis of diabetes in veterans in the southeastern U.S. is commonly delayed by about two years after hyperglycemia is present, ${ }^{14}$ years 1 and 2 prior to the index year of diagnosis could be considered as "undiagnosed diabetes," and years 3 and 4 prior to the year of diagnosis as "prediabetes" (see Appendix, Fig. 1).

\section{Identification of CVD}

CVD was captured by association of outpatient contacts and inpatient days with ICD-9 diagnostic and procedure codes typically used in the literature (see Appendix, Table 1), including coronary artery disease (CAD), cerebrovascular disease (CBD), and/or peripheral vascular disease (PVD), with and without inclusion of heart failure.

\section{VA Healthcare System Resource Use and Costs}

These were obtained from the patient-level dataset PLCOSTXX maintained by the VA's Health Economics Resource Center (http://www.herc.research.va.gov/research/default.asp, HERC). This dataset includes VA costs per veteran per FY, including costs for inpatient care, outpatient care, and pharmacy, along with inpatient days and outpatient visits. The VA does not usually generate bills for individual patients, and HERC costing is based on estimated average costs for outpatient encounters and inpatient stays that have the same demographic and discharge characteristics. All costs were expressed as 2007 dollars.

\section{Analysis}

Demographic characteristics of diabetes and control patients were compared using $t$ tests. $T$ tests were also used to compare CVD prevalence, number of days of inpatient care, number of outpatient visits, and total inpatient, outpatient, and pharmacy costs for diabetes and control patients for comparable FYs prior to, during, and after the index FY. To assess trends over time, generalized estimating equation (GEE) methods were used, including group (diabetes or control) and year as independent variables, with and without adjustment for CVD and BMI. Clustering (according to care in different VA facilities) was also accounted for in GEE. All analyses were performed using SAS version 9.2 (SAS Institute Inc., Cary, NC).

\section{RESULTS}

At the time of diabetes diagnosis (or matched time point for controls), the groups of 2,062 diabetic patients and 4,124 matched controls had similar demographic characteristics: average age 63 years, $99 \%$ male, $28.7 \%$ black, $38.6 \%$ white, and $32.7 \%$ unknown race (all $\mathrm{p}=\mathrm{ns}$ ). The average $\mathrm{BMI}$ in diabetic patients was $30.8 \mathrm{~kg} / \mathrm{m}^{2}$ and in controls was $27.8(p<0.001)$. Other diagnoses such as hypertension or dyslipidemia, smoking, levels of risk factors such as LDL cholesterol, and family history were not included in the data query for this study. Cases and controls had similar continuity of primary care, but neither was required to have visits or laboratory tests during each FY before, during, and after the index FY, which led to some variation in the number of cases and controls with data during each FY.

\section{Prevalence of CVD}

Fig. 1 shows that prevalence of CVD in the diabetic patients was significantly higher than in the controls, both before and 


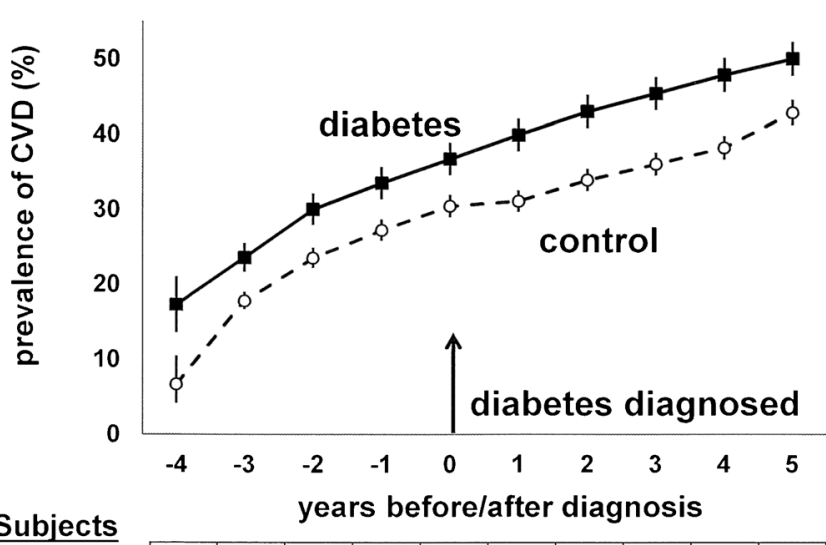

Diabetes

Control

\begin{tabular}{|l|c|c|c|c|c|c|c|c|c|}
\hline 97 & 483 & 603 & 672 & 742 & 823 & 879 & 926 & 955 & 1000 \\
\hline 20 & 734 & 933 & 1074 & 1166 & 1277 & 1373 & 1446 & 1513 & 1582 \\
\hline
\end{tabular}

Fig. 1. Prevalence of CVD (according to use of ICD-9 codes, as in "Methods," excluding CHF) in diabetic and control patients across the years before and after the year of initial diagnosis (or matched time point in controls). Shown in the tables under the figure are numbers of patients for whom data were available in each year $(p<0.001$ all years). Data shown are mean and $95 \%$ CI.

after diagnosis of diabetes $(p<0.001$ for each year, in year -4 prior to the index year of diagnosis through year +4 after diagnosis). There were fewer subjects in years -4 and -3 prior to diagnosis (Fig. 1 and subsequent figures show the number of subjects in each group with data in each year), so the precision was lower at those time points, but the trend was consistent. Patterns were similar with or without inclusion of heart failure along with CVD, and for assessment of coronary artery disease both alone and with or without heart failure (not shown). We did not determine the relative contribution of each diagnostic and procedure code to total CVD.

\section{Annual VA Healthcare System Resource Use}

Fig. 2 shows that there was increased resource use (outpatient contacts per subject per year) for patients with diabetes that began before diagnosis and continued in the years following diagnosis. The differences in the number of contacts per year were significant in year -4 prior to the year of diagnosis ( $p$ $<0.01)$ through year +4 after the year of diagnosis $(p<0.001$, all other included years). A similar trend was also seen for increased inpatient days in subjects with diabetes compared to controls, although the numbers of inpatient days were smaller and the differences were statistically significant $(p<0.05)$ only in years $-3,0$, and +1 (data not shown).

\section{Annual VA Healthcare System Costs, Component Costs, and Cost Differences}

Total VA costs per veteran per year in 2007 dollars are shown in Fig. 3. As expected, costs tended to increase over time in both diabetic and control groups as patients aged. Differences in total annual costs in diabetic vs. control groups were

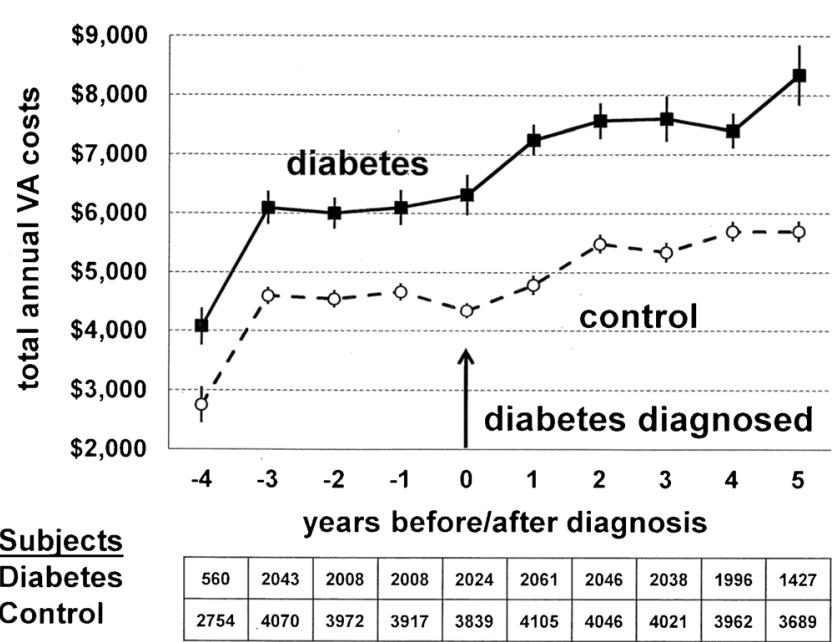

Fig. 2. Total annual VA outpatient visits per patient (obtained from HERC databases, as in "Methods") in diabetic and control patients across the years before and after the year of initial diagnosis. Data shown are mean and SEM for each year. The table below shows the number of subjects with visits during each year ( $p<0.01$ at FY-4; all other years, $p<0.001)$.

significant beginning in year $-4(\$ 4,083$ vs. $\$ 2,754)$ through year $+5(\$ 8,347$ vs. $\$ 5,700)(p<0.003$ for all of these years $)$. Thus, the difference in total VA costs was over $\$ 1,000$ per year before diabetes was diagnosed, and rose to over $\$ 2,000$ per year after diabetes was diagnosed. The pattern was similar for outpatient costs $(p<0.007$ for each of years -4 through +4$)$, inpatient costs $(p<0.05$ for most of years -4 through +5$)$, and pharmacy costs $(p<0.001$ for years -4 through +5$)$ (absolute values not shown, but cost differences shown in Table 1 ). Since there were fewer subjects with data available in the earliest and latest years of the study, we repeated the analyses

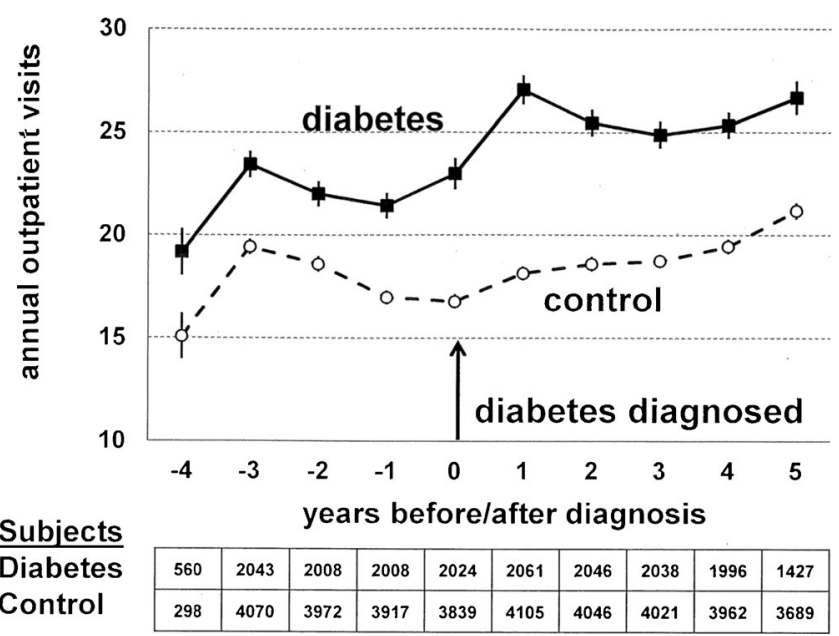

Fig. 3. Total annual VA costs per patient (obtained from HERC databases, as in "Methods") in diabetes and control patients across the years before and after the year of initial diagnosis. Tabulated values are the number of subjects during each year with cost data, including only diabetic subjects that had at least two matched control subjects during the index year; some control subjects were matched to more than one diabetic subject for this analysis. Data shown are mean and SEM $(p<0.007$ at all years). 
Table 1. Increased cost associated with diabetes in the 4 years before and after the diagnosis of diabetes

\begin{tabular}{|c|c|c|c|c|c|c|c|c|c|c|}
\hline Costs & Year & -4 & -3 & -2 & -1 & $\mathbf{0}$ & +1 & +2 & +3 & +4 \\
\hline \multirow[t]{4}{*}{ Total } & Diabetes-Control (\$) & 1329 & 1491 & 1454 & 1429 & 1968 & 2463 & 2079 & 2258 & 1703 \\
\hline & $\mathrm{SE}$ & 488 & 288 & 282 & 297 & 311 & 295 & 307 & 357 & 316 \\
\hline & $\mathrm{P}$ & 0.0026 & $<0.001$ & $<0.001$ & $<0.001$ & $<0.001$ & $<0.001$ & $<0.001$ & $<0.001$ & $<0.001$ \\
\hline & \multicolumn{10}{|c|}{ trend $p=0.045$, increase by $\$ 101$ per year } \\
\hline \multirow[t]{2}{*}{$\mathrm{N}$} & Diabetes (n) & 560 & 2043 & 2008 & 2008 & 2024 & 2061 & 2046 & 2038 & 1996 \\
\hline & Control (n) & 298 & 4070 & 3972 & 3917 & 3839 & 4105 & 4046 & 4021 & 3962 \\
\hline \multirow[t]{4}{*}{ Outpatient } & Diabetes-Control (\$) & 456 & 503 & 523 & 579 & 742 & 1236 & 1025 & 859 & 794 \\
\hline & SE & 184 & 95 & 101 & 108 & 131 & 105 & 150 & 128 & 127 \\
\hline & $\mathrm{P}$ & 0.006 & $<0.001$ & $<0.001$ & $<0.001$ & $<0.001$ & $<0.001$ & $<0.001$ & $<0.001$ & $<0.001$ \\
\hline & \multicolumn{10}{|c|}{ trend $p=0.033$, increase by $\$ 68$ per year } \\
\hline \multirow[t]{4}{*}{ Inpatient } & Diabetes-Control (\$) & 529 & 747 & 671 & 547 & 915 & 761 & 620 & 899 & 409 \\
\hline & SE & 372 & 239 & 223 & 236 & 244 & 240 & 223 & 291 & 246 \\
\hline & $\mathrm{P}$ & 0.12 & 0.004 & 0.004 & 0.04 & 0.002 & $<0.001$ & 0.008 & 0.009 & 0.118 \\
\hline & trend $p=\mathrm{ns}$ & & & & & & & & & \\
\hline \multirow[t]{4}{*}{ Pharmacy } & Diabetes-Control (\$) & 344 & 241 & 260 & 303 & 311 & 466 & 434 & 500 & 500 \\
\hline & SE & 84 & 46 & 72 & & 67 & 49 & 48 & 46 & 64 \\
\hline & $\mathrm{P}$ & $<0.001$ & $<0.001$ & $<0.001$ & $<0.001$ & $<0.001$ & $<0.001$ & $<0.001$ & $<0.001$ & $<0.001$ \\
\hline & \multicolumn{10}{|c|}{ trend $p=0.004$, increase by $\$ 32$ per year } \\
\hline
\end{tabular}

Average marginal costs in 2007 dollars for patients with diabetes compared to control patients, shown as the difference (cost of diabetic group - cost of control group) in total costs, outpatient costs, inpatient costs, and pharmacy costs, for fiscal years (FY) 4 years prior to the index year when diabetes was initially diagnosed ( $F Y 0)$, and 4 years after diabetes was diagnosed. Shown are $p$ values for $t$ tests comparing the costs in the two groups for each year, and $p$ values for trends assessed by GEE over time in the marginal costs. The values of $n$ are the numbers of patients for whom data were available in each given year (not all subjects had cost data available in every year, including the index year for some data). Based on our previous studies showing that the diagnosis of diabetes in veterans in the southeastern U.S. is commonly delayed by about two years after hyperglycemia is present, years 1 and 2 prior to the index year of diagnosis could be considered as "undiagnosed diabetes", and years 3 and 4 prior to the year of diagnosis as "prediabetes" (outlined also in Appendix, Fig. 1).

and obtained similar results using only diabetic subjects that had data available from two matched control subjects within a given year (Appendix, Fig. 2), and with diabetic and control subjects who had data available every year, which limited the analysis to FY -3 to +4 (Appendix, Fig. 3).

Component costs for the diabetic vs. control groups are shown in Fig. 4 of the appendix, and cost differences are shown in Table 1 (without adjustment for CVD and BMI). Differences in total costs averaged $\$ 1,329$ in year -4 and $\$ 1,703$ in year +4 , and rose an average of $\$ 101$ per year over this time period ( $p=0.045$ ). Although inpatient costs tended to be higher in the diabetic group compared to the controls, the difference was not significant in all years examined, and there was no significant trend for differences in inpatient costs. Differences in outpatient costs were significant in each year, and rose by an average of $\$ 68$ per subject per year $(p=0.033)$. Pharmacy cost differences were also significant in each year, and rose by an average of $\$ 32$ per subject per year $(p=0.004)$.

Table 2. VA cost per diabetic patient adjusted for year, BMI, time, and CVD using GEE model

\begin{tabular}{|c|c|c|c|c|c|}
\hline Parameter & & Estimate & SE & $95 \%$ CI & $p$ \\
\hline Intercept & & $\$ 4845$ & 554 & 3759,5931 & $<0.0001$ \\
\hline Year & & $\$ 42$ & 30 & $-17,101$ & 0.16 \\
\hline BMI & & -24 & 19 & $-62,15$ & 0.23 \\
\hline Group & Diabetes & $\$ 1748$ & 256 & 1247,2249 & $<0.0001$ \\
\hline Year*Group & Diabetes & $\$ 148$ & 71 & 9,287 & 0.037 \\
\hline CVD & & $\$ 2485$ & 192 & 2109,2862 & $<0.0001$ \\
\hline
\end{tabular}

Analysis using GEE of contributions to total VA costs in 2007 dollars in the groups of diabetic compared to control patients, with adjustments for the FY for which data was available, BMI, trends in costs over time (year"group), and costs related to CVD, as outlined in "Methods". Analysis included patients who had data each FY from -3 to $+3 ; C V D$ included heart failure.
The trends tended to be similar with adjustments for CVD and BMI (not shown).

\section{Independent Impact of Diabetes on Costs}

Since the diabetic and control groups differed in BMI and prevalence of CVD, we used GEE to evaluate the impact of diabetes on total VA costs per veteran per year in 2007 dollars, independent of such factors. Table 2 shows that from years -3 before the diagnosis of diabetes to +3 after the diagnosis, the contributions of BMI were not significant (shown as a continuous variable in Table 2 and categorical in Appendix, Table 2), and that costs did not rise significantly over this time period (i.e., with increasing age) once CVD and diabetes were taken into account. CVD (including heart failure) contributed $\$ 2,485$ to costs $(p<0.0001)$, diabetes contributed $\$ 1,748$ to costs independent of CVD $(p<0.0001)$, and the costs attributable to diabetes rose by an average of $\$ 148$ per year $(p=0.037)$.

Additional analyses were conducted to further confirm the lack of effect of obesity, and sought to identify any risk factors that might contribute to the CVD cost. With this dataset, we were able to assess the role of elevated LDL cholesterol (LDL $>130 \mathrm{mg} / \mathrm{dl}$ ) as a categorical value that contributed to the cost, but less than diabetes or CVD, and did not diminish the effects of diabetes or CVD on costs (Appendix, Table 2).

\section{DISCUSSION}

We used information in VA databases to examine the time course of the adverse associations of diabetes with veterans' health and the VA healthcare system. We selected patients who had continuity of care, and diabetic patients were matched 1:2 
with controls similar in age, gender, race/ethnicity, and facility where they received care. Compared to the control patients, the diabetic patients had higher BMI, higher prevalence of CVD, more outpatient visits, and higher annual total costs, inpatient costs, outpatient costs, and pharmacy costs. The association of diabetes with increased total costs per veteran per year persisted after adjusting for differences in BMI and prevalence of CVD, and rose by an average of $\$ 148$ per year. The differences in CVD, healthcare system resource use, and healthcare system costs between diabetic patients and controls began four years before diabetes was diagnosed, and were statistically significant. The differences in total healthcare system costs were also clinically significant, averaging over $\$ 2,000$ per year after diabetes was diagnosed and closer to $\$ 1,000$ per year before diabetes was diagnosed. While differences after diagnosis might be due in part to the bias of providers who approach patients with diagnosed diabetes differently from controls, differences prior to diagnosis are more likely to be due to the disease itself: undiagnosed diabetes and prediabetes, with associated comorbidities.

The novelty of the current study is (a) the examination of a substantial number of patients with diabetes compared to carefully matched controls, all of whom received continuous primary care for an extended period of time within the largest integrated healthcare system in the U.S., where diabetes management has been shown to be superior to that of conventional managed care, ${ }^{9}$ and where disease, resource use, and cost information were all available; and (b) the demonstration of statistically significant and clinically meaningful adverse associations of diabetes with both patients' health (CVD) and the healthcare system (resource use and costs), which began at least four years prior to the clinical diagnosis of diabetes. Since the period four years prior to the clinical diagnosis in this population has previously been shown to include both 1-2 years of undiagnosed diabetes and a prior period of prediabetes ${ }^{14}$ - asymptomatic conditions - these findings suggest that earlier identification in order to permit preventive management will require screening.

However, while many patients have some measurement of glucose levels, ${ }^{32-35}$ directed screening is presently infrequent even in high-risk populations such as those with coronary artery disease ${ }^{36}$ or prior gestational diabetes. ${ }^{37}$ In a Canadian population, glucose was measured in $37 \%$ of patients within one year and $63 \%$ within three years, but less than $1 \%$ had sensitive testing with an OGTT, and even the rate of A1c measurement was low. ${ }^{34,38}$ Screening allows for the identification of prediabetes and early diabetes, which enables the use of non-pharmacologic or pharmacologic treatment that can improve glycemic control and reduce progression of dysglycemia, ${ }^{39}$ although there is no evidence at this time that population screening can improve outcomes. ${ }^{40}$ Current recommendations are based largely on consensus, ${ }^{20,41}$ and emphasize screening of patients who are at higher risk, where screening and early treatment are more likely to be cost-effective. ${ }^{42}$

The natural history of diabetes frequently involves a longer period of gradually increasing glucose levels, followed by a shorter period with a more rapid rise shortly before diabetes is diagnosed. ${ }^{43,44}$ Thus, in most patients with clinically diagnosed diabetes, the years just prior to diagnosis likely involve a combination of prediabetes and undiagnosed diabetes. In one meta-analysis, the duration of prediabetes was estimated at 810 years. ${ }^{45}$ Such a duration is thought to be long enough to justify a screening program, if interventions aimed at prediabetes were cost-effective ${ }^{45}$, as they have been shown to be in the U.S. Diabetes Prevention Program (DPP, see below).

The period prior to the clinical diagnosis of diabetes has previously been associated with adverse effects on both health and healthcare systems. Such adverse effects have included increased $\mathrm{CVD},{ }^{28,46}$ greater utilization of primary care, ${ }^{27,47}$ and higher costs. ${ }^{29-31,48}$ In patients at KPNW who had impaired fasting glucose (IFG, with fasting plasma glucose levels $100-125 \mathrm{mg} / \mathrm{dl}$ ), marginal costs in patients with fasting glucose $110-125 \mathrm{mg} / \mathrm{dl}$ were $\$ 1,308$ more per year in 2007 dollars compared to patients who had normal fasting plasma glucose and were matched for age, sex, and year of fasting plasma glucose, and marginal costs were $\$ 881$ in patients with fasting glucose 100-109 mg/dl. ${ }^{30}$ The Medical Expenditure Panel Survey (MEPS) found marginal costs for a 50-year-old patient with new-onset diabetes to be higher by $\$ 4,431$ year in 2007 U.S. dollars, after adjusting for age, race/ethnicity, sex, and a variety of other variables, but not BMI. ${ }^{49}$ The marginal costs for KPNW patients with IFG are similar to our findings of VA marginal costs prior to the diagnosis of diabetes $(\$ 1,329$ to $\$ 1,491$ per year over the four years prior to the year of diagnosis). Both groups may have included some patients with undiagnosed early diabetes, but the largely employed KPNW population was slightly younger ( 60 vs. 63 years of age on average) and about half female, and may have had a lower disease burden than the VA population. The MEPS marginal costs for initially diagnosed diabetes were higher than the VA costs $(\$ 1,708$ to $\$ 2,463$ per year over the four years after the year of diagnosis); the American Diabetes Association estimate for marginal costs of diabetes of $\$ 6,649$ in $2007^{5}$ were higher as well. These studies also attributed a greater proportion of costs to inpatient hospitalization than the present analyses, which may reflect differences in the patient populations and/or healthcare systems or methods of data collection.

It is difficult to separate adverse effects attributable to prediabetes vs. undiagnosed diabetes in analyses of administrative databases, but one modeling approach estimated that isolated impaired glucose tolerance (IGT) was associated with greater costs than isolated IFG. ${ }^{29}$ The Norfolk study ${ }^{50}$ and a recent meta-analysis ${ }^{51}$ also provide evidence that sub-diabetic levels of glucose and A1c confer increased risk of CVD. However, we are not aware of previous reports of the adverse impact of prediabetes and early diabetes on costs independent of associated CVD.

The DPP and other studies aimed at prediabetes have demonstrated that lifestyle change and the use of medications can reduce progression to diabetes ${ }^{39}$ and the development of microvascular complications ${ }^{52}$. In patients with prediabetes, 
there may be particular benefit from achieving regression to normal glucose tolerance. ${ }^{53} \mathrm{~A} 10$-year analysis of costs in the DPP indicated that lifestyle change may be cost-effective and the use of metformin marginally cost-saving, ${ }^{54}$ and we have also projected that screening to detect prediabetes and early diabetes, combined with lifestyle change or treatment with metformin, may be cost-saving, particularly in high-risk groups. ${ }^{42,55}$ Our present findings demonstrating early adverse associations involving both health and the healthcare system prior to the diagnosis of diabetes are consistent with earlier observations, and suggest that screening and appropriate management may improve both the health of individuals and healthcare systems.

Strengths of this study include a substantial number of patients, a high percentage of minority patients, rigorous design, the use of a well-validated metric for the diagnosis of diabetes, and assessment of impact on health (CVD), resource use, and costs within an integrated healthcare system in which the quality of care is generally good compared to general U.S. managed care. ${ }^{9}$ Limitations include a predominantly male population, restriction to veterans (who tend to be older, sicker, and poorer than the general population), and restriction to the southeastern U.S. Although our findings may not apply in other settings, the consistency with earlier, less extensive studies supports generalizability. While the diabetic patients were each matched with two control patients, not all patients had analyzable data in each study year. However, the findings were unchanged when analyses included only diabetic patients who had two matched control patients with data at the same time point at any time during the study (Appendix, Fig. 2), and diabetes and control patients who all had data at each FY (could be evaluated only from FY -3 through +4 , Appendix, Fig. 3). While diabetic and control patients were matched according to care in individual VA hospital facilities, residual potential bias may exist due to care in different clinics or from different providers, and such potential clustering should be considered in further research. Another potential limitation is that underlying risk factors for diabetes and CVD may not be independent, and could contribute to increased costs. We were able to determine that obesity and increased LDL cholesterol appeared to contribute little to the diabetes-related increase in costs, but future studies should also examine the contributions of differences in blood pressure, glucose control, and other factors that were beyond the scope of this study. While we were also unable to assess CVD, resource use, and costs incurred when veterans received care outside the VA, the selection of patients who received primary care within the VA for an extended period of time renders it likely that the great majority of their care was, indeed, provided through the $\mathrm{VA}$, and that inclusion of their non-VA care would not have had a substantial impact on the study findings.

This study shows that diabetes has adverse effects on health (CVD) and the healthcare system (resource use and costs) before the diagnosis is made when patients have undiagnosed prediabetes and early diabetes. Systematic screening to detect these disorders earlier and permit prompt preventive management, therefore, may benefit both the health of patients and our healthcare systems. Since close to 2 million people are now diagnosed with diabetes each year in the U.S., ${ }^{56}$ prevention measures that could keep their marginal costs in line with those of patients with prediabetes have the potential to save up to $\$ 2$ billion a year.

Since this manuscript was submitted, it has been shown that lifestyle change in patients with prediabetes is associated with a longterm decrease in both cardiovascular and all-cause mortality, ${ }^{1}$ and the United States Preventive Services Task Force (USPSTF) has issued draft recommendations for much broader screening for diabetes and prediabetes - such as adults who are aged 45 years and above, and those who are younger but have risk factors ${ }^{2}$ (see Additional Reference List).

Acknowledgements: These findings were presented in part at the American Diabetes Association annual meeting in San Diego, CA, in June 2011.

We thank Mss. Christine Jasien and Johnita Byrd-Sellers for assistance with data management.

This work was supported in part by FDA award RO1FD003527 (L.S.P), VA award HSR\&D IIR 07-138 (L.S.P, S.L.J.), NIH awards DKO66204 (L.S.P.), UO1 DKO91958 (L.S.P. and M.K.R.), and UO1 DK098246 (L.S.P. and D.E.O.), and Cystic Fibrosis Foundation award PHILLI12AO (L.S.P).

Drs. Rhee, Phillips, Olson, and Tomolo are supported in part by the VA. This work is not intended to reflect the official opinion of the VA or the U.S. government.

The sponsors had no role in the design and conduct of the study; collection, management, analysis, and interpretation of the data; and preparation, review, or approval of the manuscript. Dr. Phillips had full access to all of the data in the study and takes responsibility for the integrity of the data and the accuracy of the data analysis.

Conflict of Interest: The authors each declare that they have no conflict of interest.

Corresponding Author: Lawrence S. Phillips, MD; Division of Endocrinology and Metabolism, Emory University, 101 Woodruff Circle, WMRB 1027, Atlanta, GA 30322, USA (email: lawrence.phillips@emory.edu).

\section{REFERENCES}

1. Miller DR, Safford MM, Pogach LM. Who has diabetes? Best estimates of diabetes prevalence in the Department of Veterans Affairs based on computerized patient data. Diabetes Care. 2004;27(Suppl 2):B10-21.

2. Maciejewski ML, Maynard C. Diabetes-related utilization and costs for inpatient and outpatient services in the Veterans Administration. Diabetes Care. 2004;27(Suppl 2):B69-73.

3. Weinstock RS, Hawley G, Repke D, Feuerstein BL, Sawin CT, Pogach LM. Pharmacy costs and glycemic control in the Department of Veterans Affairs. Diabetes Care. 2004;27(Suppl 2):B74-81.

4. Hogan P, Dall T, Nikolov P, American Diabetes A. Economic costs of diabetes in the US in 2002. Diabetes Care. 2003;26:917-32.

5. American Diabetes Association. Economic costs of diabetes in the U.S. In 2007. Diabetes Care. 2008:31:596-15.

6. American Diabetes Association. Economic costs of diabetes in the U.S. in 2012. Diabetes Care. 2013;36:1033-46.

7. Smith NL, Maynard C. The burden of diabetes-associated cardiovascular hospitalizations in Veterans Administration (VA) and non-VA medical facilities. Diabetes Care. 2004;27(Suppl 2):B27-32.

8. Asch SM, McGlynn EA, Hogan MM, Hayward RA, Shekelle P, Rubenstein L, Keesey J, Adams J, Kerr EA. Comparison of quality of care for 
patients in the Veterans Health Administration and patients in a national sample. Ann Intern Med. 2004;141:938-45

9. Kerr EA, Gerzoff RB, Krein SL, Selby JV, Piette JD, Curb JD, Herman WH, Marrero DG, Narayan KM, Safford MM, Thompson T, Mangione CM. Diabetes care quality in the Veterans Affairs Health Care System and commercial managed care: the TRIAD study. Ann Intern Med. 2004; 141:272-81.

10. Miller DR, Pogach L. Longitudinal approaches to evaluate health care quality and outcomes: the Veterans Health Administration diabetes epidemiology cohorts. J Diabetes Sci Technol. 2008;2:24-32.

11. Meduru P, Helmer D, Rajan M, Tseng CL, Pogach L, Sambamoorthi U. Chronic illness with complexity: implications for performance measurement of optimal glycemic control. J Gen Intern Med. 2007;22(Suppl 3):408-18.

12. Pogach LM, Brietzke SA, Cowan CL Jr, Conlin P, Walder DJ, Sawin CT, Group VADDGD. Development of evidence-based clinical practice guidelines for diabetes: the Department of Veterans Affairs/Department of Defense guidelines initiative. Diabetes Care. 2004;27(Suppl 2):B82-9.

13. Nichols GA, Alexander CM, Girman CJ, Kamal-Bahl SJ, Brown JB. Treatment Escalation and Rise in HbAlc Following Successful Initial Metformin Therapy. Diabetes Care. 2006;29:504-9.

14. Twombly JG, Long Q, Zhu M, Fraser LA, Olson DE, Wilson PW, Narayan KM, Phillips LS. Validity of the primary care diagnosis of diabetes in veterans in the southeastern United States. Diabetes Res Clin Pract. 2011;91:395-400

15. Twombly JG, Long Q, Zhu M, Wilson PW, Narayan KM, Fraser LA Webber BC, Phillips LS. Diabetes care in black and white veterans in the southeastern U.S. Diabetes Care. 2010;33:958-63.

16. Ziemer DC, Kolm P, Weintraub WS, Vaccarino V, Rhee MK, Twombly JG, Narayan KM, Koch DD, Phillips LS. Glucose-independent, blackwhite differences in hemoglobin Alc levels: a cross-sectional analysis of 2 studies. Ann Intern Med. 2010;152:770-7.

17. Rhee MK, Ziemer DC, Caudle J, Kolm P, Phillips LS. Use of a uniform treatment algorithm abolishes racial disparities in glycemic control. Diabetes Educ. 2008;34:655-63.

18. Phillips LS, Ziemer DC, Kolm P, Weintraub WS, Vaccarino V, Rhee MK, Chatterjee R, Narayan KM, Koch DD. Glucose challenge test screening for prediabetes and undiagnosed diabetes. Diabetologia. 2009;52:1798-807.

19. Tabaei BP, Burke R, Constance A, Hare J, May-Aldrich G, Parker SA, Scott A, Stys A, Chickering J, Herman WH. Community-based screening for diabetes in Michigan. Diabetes Care. 2003;26:668-70.

20. American Diabetes Association. Standards of medical care in diabetes2014. Diabetes Care. 2014;37(Suppl 1):S14-80.

21. Ekoe JM, Punthakee Z, Ransom T, Prebtani AP, Goldenberg $\mathbf{R}$. Screening for type 1 and type 2 diabetes. Can J Diabetes. 2014;37(Suppl 1):S12-5

22. Ryden L, Grant PJ, Anker SD, Berne C, Cosentino F, Danchin N, Deaton C, Escaned J, Hammes HP, Huikuri H, Marre M, Marx N, Mellbin L, Ostergren J, Patrono C, Seferovic P, Uva MS, Taskinen MR, Tendera M, Tuomilehto J, Valensi P, Zamorano JL, Achenbach S, Baumgartner H, Bax JJ, Bueno H, Dean V, Erol C, Fagard R, Ferrari R, Hasdai D, Hoes AW, Kirchhof P, Knuuti J, Kolh P, Lancellotti P, Linhart A, Nihoyannopoulos P, Piepoli MF, Ponikowski P, Sirnes PA, Tamargo JL, Torbicki A, Wijns W, Windecker S, De Backer G, Ezquerra EA, Avogaro A, Badimon L, Baranova E, Betteridge J, Ceriello A, FunckBrentano C, Gulba DC, Kjekshus JK, Lev E, Mueller C, Neyses L, Nilsson PM, Perk J, Reiner Z, Sattar N, Schachinger V, Scheen A, Schirmer H, Stromberg A, Sudzhaeva S, Viigimaa M, Vlachopoulos C, Xuereb RG. ESC Guidelines on diabetes, pre-diabetes, and cardiovascular diseases developed in collaboration with the EASD: the Task Force on diabetes, pre-diabetes, and cardiovascular diseases of the European Society of Cardiology (ESC) and developed in collaboration with the European Association for the Study of Diabetes (EASD). Eur Heart J. 2013;34:3035-87.

23. Canadian Task Force on Preventive Health C. Recommendations on screening for type 2 diabetes in adults. Can Med Assoc J. 2012;184:1687-96.

24. Preventive Services US. Task Force: Screening for type 2 diabetes mellitus in adults: U.S. Preventive Services Task Force recommendation statement. Ann Intern Med. 2008;148:846-54.

25. Grundy SM. Pre-diabetes, metabolic syndrome, and cardiovascular risk. J Am Coll Cardiol. 2012;59:635-43.

26. Waugh NR, Shyangdan D, Taylor-Phillips S, Suri G, Hall B. Screening for type 2 diabetes: a short report for the National Screening Committee. Health Technol Assess. 2013;17:1-90.

27. Gulliford MC, Charlton J, Latinovic R. Increased utilization of primary care 5 years before diagnosis of type 2 diabetes: a matched cohort study. Diabetes Care. 2005;28:47-52.
28. Hu FB, Stampfer MJ, Haffner SM, Solomon CG, Willett WC, Manson JE. Elevated risk of cardiovascular disease prior to clinical diagnosis of type 2 diabetes. Diabetes Care. 2002;25:1129-34.

29. Nichols GA, Arondekar B, Herman WH. Medical care costs one year after identification of hyperglycemia below the threshold for diabetes. Med Care. 2008;46:287-92

30. Nichols GA, Brown JB. Higher medical care costs accompany impaired fasting glucose. Diabetes Care. 2005;28:2223-9.

31. Nichols GA, Glauber HS, Brown JB. Type 2 diabetes: incremental medical care costs during the 8 years preceding diagnosis. Diabetes Care. 2000;23:1654-9.

32. Rifas-Shiman SL, Forman JP, Lane K, Caspard H, Gillman MW. Diabetes and lipid screening among patients in primary care: a cohort study. BMC Health Serv Res. 2008;8:25.

33. Sheehy AM, Coursin DB, Gabbay RA. Back to Wilson and Jungner: 10 good reasons to screen for type 2 diabetes mellitus. Mayo Clin Proc. 2009;84:38-42.

34. Wilson SE, Rosella LC, Lipscombe LL, Manuel DG. The effectiveness and efficiency of diabetes screening in Ontario, Canada: a population-based cohort study. BMC Pub Health. 2010;10:506.

35. Greiver M, Aliarzadeh B, Moineddin R, Meaney C, Ivers N. Diabetes screening with hemoglobin Alc prior to a change in guideline recommendations: prevalence and patient characteristics. BMC Fam Pract. 2011;12:91.

36. Kilmer G, Hughes E, Zhang X, Elam-Evans L. Diabetes and prediabetes: screening and prevalence among adults with coronary heart disease. Am J Prev Med. 2011;40:159-65.

37. Tovar A, Chasan-Taber L, Eggleston E, Oken E. Postpartum screening for diabetes among women with a history of gestational diabetes mellitus. Prev Chronic Dis. 2011;8:A124

38. Wilson SE, Lipscombe LL, Rosella LC, Manuel DG. Trends in laboratory testing for diabetes in Ontario, Canada 1995-2005: a population-based study. BMC Health Serv Res. 2009;9:41.

39. Knowler WC, Barrett-Connor E, Fowler SE, Hamman RF, Lachin JM, Walker EA, Nathan DM. Diabetes Prevention Program Research G: Reduction in the incidence of type 2 diabetes with lifestyle intervention or metformin. N Engl J Med. 2002;346:393-403.

40. Sandbaek A, Griffin SJ, Sharp SJ, Simmons RK, Borch-Johnsen K, Rutten GE, van den Donk M, Wareham NJ, Lauritzen T, Davies MJ, Khunti K. Effect of early multifactorial therapy compared with routine care on microvascular outcomes at 5 years in people with screen-detected diabetes: a randomized controlled trial: the ADDITION-Europe Study. Diabetes Care. 2014;37:2015-23.

41. Ekoé J-M, Punthakee Z, Ransom T, Prebtani APH, Goldenberg R. Screening for Type 1 and Type 2 Diabetes. Can J Diabetes. 2013;37(Supplement 1):S12-5

42. Chatterjee R, Narayan KM, Lipscomb J, Jackson SL, Long $\mathbf{Q}$, Zhu M, Phillips LS. Screening for diabetes and prediabetes should be cost-saving in patients at high risk. Diabetes Care. 2013;36:1981-7.

43. Mason CC, Hanson RL, Knowler WC. Progression to type 2 diabetes characterized by moderate then rapid glucose increases. Diabetes. 2007;56:2054-61.

44. Tabak AG, Jokela M, Akbaraly TN, Brunner EJ, Kivimaki M, Witte DR. Trajectories of glycaemia, insulin sensitivity, and insulin secretion before diagnosis of type 2 diabetes: an analysis from the Whitehall II study. Lancet. 2009;373:2215-21.

45. Bertram MY, Vos T. Quantifying the duration of pre-diabetes. Aust N Z J Public Health. 2010;34:311-4.

46. Norhammar A, Tenerz A, Nilsson G, Hamsten A, Efendic S, Ryden L, Malmberg $\mathbf{K}$. Glucose metabolism in patients with acute myocardial infarction and no previous diagnosis of diabetes mellitus: a prospective study. Lancet. 2002;359:2140-4

47. Gulliford MC, Latinovic R, Charlton J. Diabetes diagnosis, resource utilization, and health outcomes. Am J Manag Care. 2008;14:32-8.

48. Zhang Y, Dall TM, Mann SE, Chen Y, Martin J, Moore V, Baldwin A, Reidel VA, Quick WW. The economic costs of undiagnosed diabetes. Popul Health Manag. 2009;12:95-101.

49. Trogdon JG, Hylands T. Nationally representative medical costs of diabetes by time since diagnosis. Diabetes Care. 2008;31:2307-11.

50. Khaw KT, Wareham N, Bingham S, Luben R, Welch A, Day N. Association of hemoglobin Alc with cardiovascular disease and mortality in adults: the European prospective investigation into cancer in Norfolk. Ann Intern Med. 2004;141:413-20.

51. Sarwar N, Aspelund T, Eiriksdottir G, Gobin R, Seshasai SR, Forouhi NG, Sigurdsson G, Danesh J, Gudnason V. Markers of dysglycaemia and risk of coronary heart disease in people without diabetes: Reykjavik prospective study and systematic review. PLoS Med. 2010;7:e1000278. 
52. Gong Q, Gregg EW, Wang J, An Y, Zhang P, Yang W, Li H, Li H, Jiang Y, Shuai Y, Zhang B, Zhang J, Gerzoff RB, Roglic G, Hu Y, Li G, Bennett PH. Long-term effects of a randomised trial of a 6-year lifestyle intervention in impaired glucose tolerance on diabetes-related microvascular complications: the China Da Qing Diabetes Prevention Outcome Study. Diabetologia. 2011;54:300-307.

53. Perreault L, Pan Q, Mather KJ, Watson KE, Hamman RF, Kahn SE. Diabetes Prevention Program Research G: Effect of regression from prediabetes to normal glucose regulation on long-term reduction in diabetes risk: results from the Diabetes Prevention Program Outcomes Study. Lancet. 2012;379:2243-51.

54. Diabetes Prevention Program Research Group. The 10-year cost-effectiveness of lifestyle intervention or metformin for diabetes prevention: an intent-totreat analysis of the DPP/DPPOS. Diabetes Care. 2012;35:723-30.

55. Chatterjee R, Narayan KM, Lipscomb J, Phillips LS. Screening adults for pre-diabetes and diabetes may be cost-saving. Diabetes Care. 2010;33:1484-90.
56. http://www.cdc.gov/diabetes/pubs/statsreport14/national-diabetes-report-web.pdf [article online], 2014. Accessed 13 Oct 2014

\section{ADDITIONAL REFERENCE LIST}

1. Li G, Zhang $\mathbf{P}$, Wang J, An Y, Gong Q, Gregg EW et al. Cardiovascular mortality, all-cause mortality, and diabetes incidence after lifestyle intervention for people with impaired glucose tolerance in the Da Qing Diabetes Prevention Study: a 23-year follow-up study. Lancet Diabetes Endocrinol 2014;2(6):474-480.

2. US Preventive Services Task Force. Draft recommendation statementabnormal glucose and type 2 diabetes mellitus in adults: screening. Updated October 6, 2014. http://www.uspreventiveservicestaskforce.org/Page/Document/RecommendationStatementDraft/screening-for-abnormal-glucoseand-type-2-diabetes-mellitus\#Pod9. Accessed 11 May 2014. 